\title{
Migration and aspirations - are migrants trapped on a hedonic treadmill?
}

\author{
Mathias Czaika ${ }^{1 *}$ and Marc Vothknecht ${ }^{2^{*}}$
}

\author{
* Correspondence: \\ mathias.czaika@qeh.ox.ac.uk; \\ marc.vothknecht@gmx.de \\ ${ }^{1}$ International Migration Institute, \\ Department for International \\ Development University of Oxford, \\ OX1 3TB Oxford, UK \\ ${ }^{2}$ German Institute for Economic \\ Research (DIW Berlin), Mohrenstraße \\ 58, 10117 Berlin, Germany
}

\begin{abstract}
Based on longitudinal information from two waves of the Indonesian Family and Life Survey (IFLS) in 2000 and 2007, we find evidence that migrants are self-selected along higher individual aspirations acquired (or, inherited) before migration. About 70 per cent of aspiration differentials can be explained by factors such as young age, good education, or superior socio-economic background, while the residual seems to be linked to an individual pre-disposition for higher aspirations. However, despite the fact that migration is economically beneficial for most migrants, the migration experience itself seems to further increase economic aspirations, hereby trapping migrants on a 'hedonic treadmill'. JEL classification: D03; J61; R23

Keywords: Internal migration; Migration behaviour; Aspirations; Indonesia
\end{abstract}

\section{Introduction}

The causes and consequences of internal migration in developing countries have been analysed extensively in the economic and social science literature (Greenwood 1997; Lucas 1997). Building on this literature, this paper adds new insight on the interaction between the individual decision to migrate and aspirations for the future, by asking whether aspirations are the cause or rather the consequence of migration, or both.

Using longitudinal household survey data from two waves of the Indonesian Family Life Survey (IFLS) collected in 2000 and 2007, our research is motivated by a puzzle we have identified by comparing recent migrants and non-migrants with respect to their current subjective well-being and their (economic) aspirations for the future. In terms of current well-being, we find a rural-urban divide with higher levels of subjective well-being reported in urban areas, which is a known phenomenon also in other contexts (see Knight \& Gunatilaka (2010) for China, or Fafchamps \& Shilpi (2008) for Nepal). Interestingly, no significant differences in subjective well-being are observed between those respondents with recent migration experience and the non-migrants, neither in rural nor in urban contexts. However, migrants express strikingly higher levels of aspirations for the future than non-migrants, with only weak differences between rural and urban populations. While migrants are as (un-) satisfied with their current economic situation as non-migrants, migrants are much more ambitious about the future. The key question is now: What explains this difference in aspirations? Are migrants simply a self-selected group of individuals with higher aspirations? Or, are these higher levels of aspirations rather a consequence of the migration experience 
itself, that is, does the migration experience generate higher aspirations? And if there is a relationship between aspirations and the decision to migrate, is it non-linear with highest migration propensities for individuals with 'middle-range' aspirations?

Section 2 discusses the concept of aspirations by providing a theoretical rationale for its relevance as an individual-specific cause and consequence of migration decisions, and specifies hypotheses to be tested in this paper. Section 3 provides background information on migration in Indonesia since the Asian crisis in 1997 and describes the panel dataset that we use for the analysis. Section 4 reports the results from our estimates on the determinants of aspirations and the role of migration experience, explores whether aspirations trigger the decision for migration, investigates whether this aspiration-migration link is non-linear, and finally, we assess the role of migration selfselection along higher aspirations. Section 5 summarises and concludes.

\section{Aspirations as a cause and consequence of migration}

This study proposes a theoretical frame for understanding migration that goes beyond the standard economic approach of rational and utility-maximizing individuals or households. We conceptualise migration as a function of an individual's capability for migration, with this capability being a combination of two individual-specific 'capacities', the 'capacity to aspire' and the 'capacity to realise'.

People's capacity to aspire describes the set of factors that determine the difference between an individual's current level of well-being and its aspired future level of well-being. Thus, individual $i$ with a (pre-migration) level of subjective well-being $w_{i, t}$ might consider migration as a way to achieve his aspired future level of well-being, if $w_{i, t}^{a}=w_{i, t+1}>w_{i, t}$. We call the difference between the actual and the aspired level of subjective well-being the aspiration gap $g_{i, t}$, defined as: ${ }^{1}$

$$
g_{i, t}\left(w_{i, t}^{a}, w_{i, t}\right) \equiv w_{i, t}^{a}-w_{i, t}
$$

Hereby, the capacity to aspire, or the aspiration gap, includes not only the ability to set goals and generate aspirations, but also knowledge of how to achieve those goals (Dalton, Ghosal, \& Mani, 2010). In the following, we define aspiration gaps as the motivation to achieve personal economic progress, which can be the result of a conscious or unconscious drive to increase subjective well-being.

Psychological research shows that aspirations, or achievement motivation, can either be an inherited or acquired character trait, often formed at an early age (Quaglia \& Cobb 1996), but are also a product of a stimulating social environment (Collier 1994). Thus, many factors may affect people's aspiration formation, ranging from the individual personality, socialisation, education, to access to information and networks, and eventually the migration experience itself. People's awareness of social, economic and political opportunities elsewhere, transmitted through modern mass media, the internet, or social networks, may thereby increase (life) aspirations (de Haas 2010).

However, aspirations as such do not necessarily enable an individual to leave the social, economic and sometimes even the political context. Potential migrants not only need to have the 'capacity to aspire' (cf. Appadurai 2004; Ray 2006), but also the 'capacity to realise' a migration project (Carling 2004; de Haas 2010). This capacity to realise migration is the result of the endowment with various extrinsic economic, social, 
human, or political capabilities (Sen 1985) that may enable migration. A lack of these capabilities constrains the extent to which people can actually migrate.

In general, the capability for migration can be thought of as a necessary condition for a person to be considered a potential migrant. However, persons with sufficient capacities to aspire and realise migration may never decide to migrate, while the absence of the capability for migration makes voluntarily migration very unlikely.

The question arising is whether people, driven by the power of strong aspirations, work on their capabilities to overcome their 'involuntary immobility' (cf. Carling 2002), or whether individuals rather adjust their aspirations downwards to avoid continued unhappiness because of unfulfilled aspirations. Appadurai (2004) calls the latter phenomenon an aspiration trap, because without the 'capacity to aspire' people are likely to remain in a poverty trap which is characterised by a low level of individual capabilities that does not allow people to improve their well-being. On a larger scale, aspiration traps prevent broader economic and social change in a society.

Migration itself may resolve such an 'aspiration trap' by forming aspirations, for instance through the adaptation to new lifestyles or the emulation of role models and new peers ('reference group substitution') (Rao \& Walton 2004) ${ }^{2}$. The capacity to realise and the capacity to aspire are mutually interdependent. Aspirations can stimulate behaviour leading to an improvement of capabilities, and, at the same time, aspirations are the consequence of inherited and/or socially acquired capabilities. Migration is thereby an important transmission mechanism linking the capacity to aspire and the capacity to realise. Aspirations are hence expected to be endogenous, with the aspired goals for the future being likely to change (normally, to increase) with the migration experience itself. Migration as an investment in capabilities can widen the set of (known) opportunities, or the 'aspirational window' (cf. Ray 2006), by increasing people's capacity to aspire. Thus, we hypothesise that the decision to migrate is both initiated and perpetuated by an ex ante aspiration gap reflecting people's desire to realise economic, social, human or political opportunities which are within their aspirational windows.

However, aspirational windows do not necessarily close with migration, but might even enlarge if the returns to migration in terms of enhanced well-being are lower than expected, or if the migration experience coincides with a rising awareness of even better opportunities that lead to even higher aspirations. This phenomenon, known as the 'hedonic treadmill' may explain our initial finding that migrants do not report significantly higher levels of subjective well-being compared to non-migrants while having significantly larger aspirations. Even if migration has an actual positive impact on capabilities (for instance, through better education, higher income, or improved access to health services), the post-migration aspirational window can be larger than before. Awareness about new opportunities combined with stronger feelings of relative deprivation may have a negative effect on a migrant's level of subjective well-being and/ or aspirations about the future.

Finally, we claim that a positive aspiration gap creates the impetus for a behavioural action to close it, such as a decision to migrate. However, what size of the aspiration gap renders the strongest impetus for migration? Intuitively, we would assume that the aspiration-migration link is non-linear, that is, very low or very high aspiration gaps lead to significantly lower migration propensities than 'middle-range' aspirations, which are significant but achievable, and thus, realistic aspirations. People with low aspiration 
gaps have relatively low incentives to migrate, but also people with very large aspiration gaps have limited interest in diminishing the gap. Why? Mainly because any actions and investments taken (including migration) may not be conducive to significantly reduce the extra-large aspiration gap and it would remain large even after migration. In this case, migration may be considered not worth to undertake the associated risk of failure. A persistent aspiration gap may also be a source of frustration and unhappiness, and a more likely 'cognitive' response is to adjust aspirations downwards. This is the reason why we expect to find less migrants among those with very high aspiration gaps. Thus, while a positive aspiration gap is essential to motivate people to migrate, this gap should not be too large in order to avoid frustration and emotional loss. We therefore hypothesise that future migrants form middle-range aspirations, which give the strongest impetus for closing an achievable aspiration gap through investing in migration. In the following, we outline four hypotheses that this paper will test.

\section{Hypotheses about the aspirations-migration nexus}

First, we consider that self-selection is an important explanation for the differences in aspirations between migrants and non-migrants. The fact that migrants have higher aspirations (after migration) might simply be the result of this self-selection process. Many studies show that, on average, migrants are younger, better educated and relatively well-endowed compared to non-migrants, which are factors which tend to correlate with higher life aspirations. Thus, we presume that potential future migrants report higher aspirations already before migrating because their capacities to aspire and to realise migration, respectively, are affected by similar individual characteristics.

Second, we argue that, already before the migration experience, future migrants have a unique capacity to aspire, which goes beyond the effects of some stylized (migration) factors such as age, education, socio-economic background. We therefore hypothesise that the differences in aspiration gaps between migrants and non-migrants do not disappear when simultaneously controlling for differences in socio-economic characteristics. We argue that at least part of the difference in aspirations gaps between migrants and non-migrants cannot be explained by measurable characteristics or capabilities such as age, education or the endowment with other economic, social or human resources. Thus, even if the group of permanent non-migrants would have exactly the same observable socio-economic characteristics than the group of future migrants, they would have smaller aspiration gaps which -as one consequence- make them less prone to migration. We hence claim that migrants possess certain intrinsic aspirations that go beyond the aspirational levels that can be explained by individual and socio-economic characteristics. However, a discussion about whether such 'super-aspirations' are genetically inherited or rather socially acquired goes beyond the scope of this paper.

Third, we hypothesise that migration itself leads to higher aspirations. Without excluding the possibility that migrants already have higher aspirations before migrating, there are various reasons to think why aspiration gaps may also be driven by the migration experience itself. For instance and as already mentioned, migration may expand the 'aspirational window', i.e. the awareness about new opportunities, which most likely corresponds with increasing aspirations. Another possible source for rising aspirations are feelings of relative deprivation as a consequence of social comparisons with new 
peer groups at the destination site ('reference group substitution', see Stark and Taylor $(1991))^{3}$. Migrants may also have significantly higher aspirations than non-migrants because they adapt their aspirations to the level of risks they have taken to achieve their initial aspiration level (see Selten (1998) for a so-called aspiration adaptation theory).

Finally, we inquire whether the hypothesised aspiration-migration relationship is non-linear. In fact, we hypothesise that both very low and very high aspiration gaps lead to lower migration propensities than "middle-range aspirations", that is, significant but achievable aspirations. The hypothesised non-linear reverse-causal relationship between aspirations and migration behaviour creates an 'endogeneity puzzle', which we aim to disentangle empirically for the Indonesian context. To summarise, we will test the following hypotheses:

Hypothesis 1a: Future migrants have higher aspirations than non-migrants, because future migrants are self-selected according to aspiration-enhancing characteristics such as being of young age, well-educated, or better socio-economic background.

Hypothesis 1b: Future migrants have higher aspirations than non-migrants because of a unique capacity or disposition for 'super-aspirations'.

Hypothesis 2: Past migrants have higher aspirations than non- or future migrants because the migration experience itself increases aspirations.

Hypothesis 3: Potential migrants with moderate aspiration gaps have a higher migration propensity than individuals with very low or very high aspirations.

\section{Background and data}

\section{Local context}

Before describing the data in more detail, we give a brief overview of Indonesia's recent socio-political development and the patterns of internal migration. Indonesia, the fourth most populous nation in the world, has undergone a period of major political, economic, and social transitions after the fall of the New Order regime (Orde Baru) in the wake of the Asian financial crisis in 1998. More than a decade later, the country is considered a stable democracy with promising long-term economic prospects (Worldbank 2011).

Migration has always played an important role in Indonesia, with around 6 per cent of the total population living outside their province of birth already in 1930 (Volkstelling 1930). Consisting of more than 17,000 islands, the Indonesian archipelago is characterized by an immense cultural and linguistic diversity as well as substantial socio-economic disparities, particularly between the politically and economically dominating main island of Java and the outer islands. During the autocratic rule of President Suharto from 1967 to 1998, the controversial "transmigration program" was extended, which resulted in (forced) displacements of millions of poor households from the densely populated island of Java to less densely populated regions (Marr, 1990). This large-scale resettlement program, intended to ease population pressure on Java and to foster economic development outside Java, has caused ethno-religious tensions in the receiving regions and is considered a major trigger of widespread communal violence in the early post-Suharto period (Østby, Urdal, Tadjoeddin, Murshed, \& Strand 2011).

With Indonesia's major transition to a more democratic, decentralized and marketoriented system after the fall of the New Order, the transmigration program was discarded 
and existing legal barriers to internal migration where removed. By 2000, the number of inter-province migrants had increased to about 10 per cent (Van Lottum \& Marks, 2010), with rural-urban migration as the major contributor to intensified urbanization processes (United Nations 2008).

\section{The Indonesian family life survey data}

We study the interrelations between individual aspirations and the decision to migrate using data from the Indonesian Family Life Survey (IFLS), a large-scale, longitudinal household and community survey representative of about 83 per cent of the Indonesian population (Strauss et al. 2009). We employ the third (ILFS3 in 2000) and the fourth wave (IFLS4 in 2007/08) of the IFLS, which provides us with a sample of 34,341 adult respondents from 12,900 households, of which 17,564 individuals are observed in both waves. The community survey additionally offers detailed information on the characteristics of the 320 communities in the sample ${ }^{4}$.

The longitudinal data of the IFLS allows a detailed analysis of internal migration patterns. For this study, we particularly focus on (i) exceptionally rich information on the respondent's past migration movements; and (ii) a module on subjective well-being that was included in IFLS3 for the first time. The migration module provides a complete migration history from birth to date for each adult respondent in the survey. The module includes information on the location of origin, the destination, the date of moving, the reason to move, and the co-movers. Migration decisions are mostly work-related, while other important motivations to move are related to family and education. Where appropriate, we will distinguish these different reasons to migrate in the analysis ${ }^{5}$.

Our main variable of interest is people's aspirations about their future economic wellbeing given their current situation. We construct the variable aspiration gap based on information provided by the respondents' assessments of their current and expected future well-being, respectively ${ }^{6}$. Combining this information allows us to calculate an aspiration gap according to equation (1), i.e. the difference between current and aspired well-being in the future, with a one year horizon in the 2000 survey and a five year horizon in the 2007 survey $^{7}$.

On average, we observe higher aspiration gaps in 2007, which seems both related to the longer, five year time horizon for aspired future well-being and the more prosperous economic outlook in 2007, compared to the political and economic turbulences in the aftermath of the Asian financial crisis and the fall of the New Order regime. More than 50 per cent of the respondents perceive their relative economic situation as 'average' (i.e. on step three of the six-step ladder), while aspiration gaps tend to decrease with increasing economic well-being.

Table 1 illustrates the puzzle which motivates our research. We compare respondents with and without recent (i.e. between 1997 and 2000) migration experience with respect to their subjective (current) well-being and their aspirations for the future, and further distinguish by urban and rural locations. First, we find a rural-urban divide with higher levels of well-being reported in urban areas (both for migrants and nonmigrants $)^{8}$, while aspirations for the future do not differ significantly between respondents in urban and rural locations. The opposite pattern is observed when comparing recent migrants to non-migrants. While recent migrants do not express significantly 
Table 1 Past migrants and non-migrants: status quo well-being and future aspirations

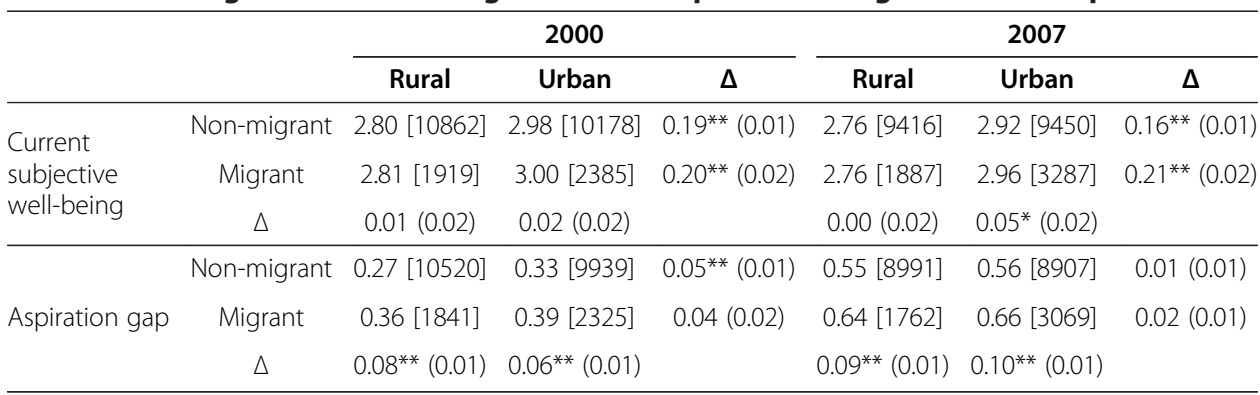

Notes: No of observations in brackets, standard errors in parentheses. ** (*) significant at $0.1 \%$ (1\%) level. In 2000, survey respondents were asked about their aspirations in the next year, whereas in the 2007 survey, respondents were asked about aspirations of well-being in a five year horizon. The respondents were asked to imagine a six-step ladder with the poorest (richest) people on the first (sixth) step, and to state their current as well as their expected future position.

different levels of subjective well-being compared to non-migrants, they express much higher levels of future aspirations than non-migrants, with almost no or only weak differences between rural and urban contexts. Whether high aspirations are rather the cause or the consequence of migration, i.e. whether higher levels of aspirations for migrants are independent from, or rather the result of their migration experience is the guiding question for the subsequent analysis.

\section{Empirical results}

\section{The determinants of aspiration}

Table 2 reports the results for the analysis on the determinants for aspirations. By estimating aspiration gaps, we can identify what observable characteristics of the individual respondent explain the differences between migrants and non-migrants ${ }^{9}$. In the two rounds of the IFLS (2000 and 2007), time horizons for achieving the aspired subjective well-being differ, being one year in 2000 and five years in 2007 .

Comparison of the two subsamples of migrants and non-migrants reveals that both groups have very similar patterns of other aspiration-enhancing factors. First, and maybe foremost, age is a crucial determinant of individual aspirations. For both time horizons ( 1 and 5 years), young adults, aged 15-24, show the highest aspiration gaps, which then continuously decline with age. Differences between migrants and nonmigrants are marginal and not significant, implying that young people have higher aspirations, irrespective of their migration experience. Besides age, education plays a key role in explaining aspiration gaps. Less educated respondents appear to have lower aspirations, with no (or only weakly) significant differences in the effects of education on aspirations between migrants and non-migrants. We also find the level of economic activity, measured in the numbers of hours worked, to be positively associated with aspirations for the future.

Furthermore, individuals of poor households (i.e. of the lowest income quartile), have significantly lower future aspirations than wealthier households. This seems to indicate a positive link between the 'capacity to realise' and the 'capacity to aspire' and provides evidence for the existence of a 'vicious cycle' of low aspirations and poverty (Appadurai 2004). Another indication for a positive association between capabilities and aspirations 
Table 2 Determinants of aspirations: differences between migrants and non-migrants

\begin{tabular}{|c|c|c|c|c|c|c|c|c|}
\hline \multirow[b]{2}{*}{ DV: Aspiration gap } & \multicolumn{4}{|c|}{1 year aspirations (2000 Survey) } & \multicolumn{4}{|c|}{5 year aspirations (2007 Survey) } \\
\hline & $\begin{array}{l}\text { Full sample } \\
\text { (1) }\end{array}$ & $\begin{array}{l}\text { Migrants } \\
\text { (2) }\end{array}$ & $\begin{array}{l}\text { Non-migrants } \\
\text { (3) }\end{array}$ & $\begin{array}{c}\text { Test } \\
(2)>(3)\end{array}$ & $\begin{array}{l}\text { Full sample } \\
\text { (4) }\end{array}$ & $\begin{array}{l}\text { Migrants } \\
\text { (5) }\end{array}$ & $\begin{array}{c}\text { Non-migrants } \\
(6)\end{array}$ & $\begin{array}{c}\text { Test } \\
(5)>(6)\end{array}$ \\
\hline Past migration & $0.04^{* *}(0.002)$ & & & & $0.05^{* * *}(0.000)$ & & & \\
\hline Age group: $25-39$ years $^{\mathrm{a}}$ & $-0.02(0.178)$ & $-0.04(0.121)$ & $-0.01(0.481)$ & $(0.153)$ & $-0.09^{* * *}(0.000)$ & $-0.07^{*}(0.038)$ & $-0.09^{* * *}(0.000)$ & $(0.669)$ \\
\hline Age group: $40-65$ years & $-0.13^{* * *}(0.000)$ & $-0.14^{* *}(0.002)$ & $-0.13^{* * *}(0.000)$ & $(0.383)$ & $-0.23^{* * * *}(0.000)$ & $-0.27^{* * *}(0.000)$ & $-0.22^{* * * *}(0.000)$ & $(0.207)$ \\
\hline Age group: $>65$ years & $-0.18^{* * * *}(0.000)$ & $-0.28^{* *}(0.002)$ & $-0.17^{* * *}(0.000)$ & $(0.126)$ & $-0.38^{* * *}(0.000)$ & $-0.41^{* * *}(0.000)$ & $-0.38^{* * *}(0.000)$ & $(0.393)$ \\
\hline Men & $-0.01(0.265)$ & $0.04(0.143)$ & $-0.02^{*}(0.045)$ & $(0.985)$ & $0.04^{*}(0.011)$ & $0.04(0.314)$ & $0.04^{*}(0.023)$ & $(0.498)$ \\
\hline No education ${ }^{b}$ & $-0.00(0.781)$ & $-0.0076(0.908)$ & $-0.00(0.762)$ & $(0.485)$ & $-0.08^{* * * *}(0.000)$ & $-0.16(0.124)$ & $-0.07^{* * *}(0.001)$ & $(0.189)$ \\
\hline Junior high school & $0.05^{* * *}(0.000)$ & $0.03(0.368)$ & $0.05^{* * *}(0.000)$ & $(0.212)$ & $0.06^{* * *}(0.000)$ & $0.01(0.753)$ & $0.07^{* * *}(0.000)$ & $(0.121)$ \\
\hline Senior high school & $0.07^{* * *}(0.000)$ & $0.07^{*}(0.024)$ & $0.07^{* * *}(0.000)$ & $(0.535)$ & $0.12^{* * *}(0.000)$ & $0.07(0.103)$ & $0.13^{* * *}(0.000)$ & $(0.097)$ \\
\hline Higher education & $0.11^{* * *}(0.000)$ & $0.10^{*}(0.026)$ & $0.13^{* * *}(0.000)$ & $(0.280)$ & $0.20^{* * *}(0.000)$ & $0.15^{* *}(0.005)$ & $0.20^{* * *}(0.000)$ & $(0.189)$ \\
\hline Edu gap:own vs. highest in the $\mathrm{HH}$ & $-0.00(0.921)$ & $0.03(0.115)$ & $-0.00(0.597)$ & $(0.948)$ & $0.01(0.060)$ & $-0.00(0.838)$ & $0.02^{*}(0.034)$ & $(0.196)$ \\
\hline Hours worked per week & $0.00^{* * *}(0.001)$ & $0.00(0.410)$ & $0.00^{* * *}(0.001)$ & $(0.330)$ & $0.00^{*}(0.016)$ & $0.00(0.166)$ & $0.00(0.071)$ & $(0.717)$ \\
\hline Total monthly income(ln) & $0.00(0.730)$ & $-0.00(0.433)$ & $0.00(0.450)$ & $(0.176)$ & $-0.00(0.947)$ & $-0.01^{*}(0.039)$ & $0.00(0.318)$ & $(0.013)$ \\
\hline Community participation & $0.03^{* *}(0.003)$ & $0.01(0.743)$ & $0.04^{* *}(0.002)$ & $(0.218)$ & $0.00(0.842)$ & $-0.00(0.907)$ & $0.00(0.758)$ & $(0.409)$ \\
\hline Married & $0.03^{* *}(0.009)$ & $0.08^{* *}(0.003)$ & $0.02(0.206)$ & $(0.984)$ & $0.02(0.121)$ & $0.02(0.575)$ & $0.02(0.168)$ & $(0.462)$ \\
\hline $\mathrm{HH}$ head & $-0.03^{*}(0.035)$ & $-0.08^{*}(0.018)$ & $-0.02(0.264)$ & $(0.038)$ & $-0.07^{* * * *}(0.000)$ & $-0.07(0.128)$ & $-0.07^{* * * *}(0.000)$ & $(0.551)$ \\
\hline Age HH head: $40-65$ years $^{a}$ & $0.02(0.135)$ & $0.03(0.289)$ & $0.01(0.304)$ & $(0.718)$ & $-0.05^{* *}(0.006)$ & $-0.05(0.198)$ & $-0.04^{*}(0.021)$ & $(0.407)$ \\
\hline Age HH head: $>65$ years & $0.01(0.714)$ & $0.02(0.706)$ & $0.00(0.956)$ & $(0.624)$ & $-0.05^{*}(0.049)$ & $-0.11(0.108)$ & $-0.04(0.166)$ & $(0.146)$ \\
\hline $\mathrm{HH}$ expenditure $-1^{\mathrm{st}}$ quantile ${ }^{c}$ & $0.01(0.357)$ & $0.0(0.915)$ & $0.01(0.365)$ & $(0.419)$ & $-0.05^{* * *}(0.000)$ & $-0.06(0.142)$ & $-0.05^{* *}(0.001)$ & $(0.383)$ \\
\hline $\mathrm{HH}$ expenditure $-4^{\text {th }}$ quantile & $0.01(0.200)$ & $-0.01(0.783)$ & $0.02(0.118)$ & $(0.181)$ & $0.02(0.285)$ & $-0.01(0.738)$ & $0.02(0.167)$ & $(0.173)$ \\
\hline Household with farm income & $0.01(0.542)$ & $0.00(0.952)$ & $0.01(0.465)$ & $(0.417)$ & $0.02(0.113)$ & $0.05(0.175)$ & $0.02(0.280)$ & $(0.804)$ \\
\hline Household with non-farm business & $0.02^{*}(0.013)$ & $0.03(0.260)$ & $0.02^{*}(0.033)$ & $(0.599)$ & $0.04^{* *}(0.003)$ & $0.04(0.178)$ & $0.03^{*}(0.011)$ & $(0.626)$ \\
\hline
\end{tabular}


Table 2 Determinants of aspirations: differences between migrants and non-migrants (Continued)

\begin{tabular}{|c|c|c|c|c|c|c|c|c|}
\hline Female headed $\mathrm{HH}$ & $-0.00(0.787)$ & $-0.02(0.484)$ & $-0.00(0.802)$ & $(0.307)$ & $0.04^{*}(0.018)$ & $0.05(0.205)$ & $0.04^{*}(0.048)$ & $(0.605)$ \\
\hline $\mathrm{HH}$ adults & $-0.00(0.411)$ & $-0.01^{*}(0.024)$ & $-0.00(0.934)$ & $(0.019)$ & $0.00(0.492)$ & $0.01(0.139)$ & $0.00(0.823)$ & $(0.880)$ \\
\hline HH children age $0-4$ & $0.01(0.059)$ & $-0.01(0.396)$ & $0.02^{*}(0.019)$ & $(0.045)$ & $0.02^{*}(0.045)$ & $0.01(0.614)$ & $0.02(0.067)$ & $(0.402)$ \\
\hline HH children age 5-9 & $-0.00(0.538)$ & $0.02(0.165)$ & $-0.01(0.221)$ & $(0.962)$ & $0.02^{*}(0.045)$ & $-0.00(0.875)$ & $0.02^{*}(0.016)$ & $(0.136)$ \\
\hline HH children age $10-14$ & $0.00(0.935)$ & $-0.04^{* *}(0.008)$ & $0.01(0.268)$ & $(0.002)$ & $-0.00(0.785)$ & $-0.05^{*}(0.047)$ & $0.00(0.597)$ & $(0.029)$ \\
\hline Household with TV & $0.01(0.277)$ & $0.03(0.244)$ & $0.01(0.472)$ & $(0.792)$ & $-0.00(0.801)$ & $-0.00(0.924)$ & $-0.00(0.921)$ & $(0.481)$ \\
\hline Rural HH & $0.00(0.899)$ & $0.00(0.886)$ & $0.00(0.836)$ & $(0.520)$ & $0.01(0.355)$ & $0.02(0.612)$ & $0.01(0.464)$ & $(0.570)$ \\
\hline Average $\mathrm{HH}$ asset value & $0.00(0.868)$ & $0.01(0.512)$ & $-0.00(0.750)$ & $(0.770)$ & $-0.01(0.104)$ & $-0.01(0.713)$ & $-0.02(0.079)$ & $(0.751)$ \\
\hline Ethnic fractionalization & $0.04(0.135)$ & $-0.03(0.538)$ & $0.06^{*}(0.033)$ & $(0.067)$ & $-0.03(0.401)$ & $-0.03(0.685)$ & $-0.01(0.801)$ & $(0.394)$ \\
\hline Constant & $0.28^{* *}(0.003)$ & $0.29(0.081)$ & $0.32^{* *}(0.006)$ & & $0.96^{* * *}(0.000)$ & $0.92^{* * *}(0.000)$ & $1.01^{* * * *}(0.000)$ & \\
\hline Province dummies & Yes & Yes & Yes & Yes & Yes & Yes & Yes & Yes \\
\hline$N$ & 23109 & 3747 & 19362 & & 20717 & 3598 & 17119 & \\
\hline$R^{2}$ & 0.043 & 0.055 & 0.042 & & 0.085 & 0.077 & 0.081 & \\
\hline $\operatorname{adj} . R^{2}$ & 0.041 & 0.043 & 0.040 & & 0.082 & 0.065 & 0.079 & \\
\hline$A / C$ & 41654.6 & 7165.8 & 34470.2 & & 45748.3 & 8302.7 & 37463.4 & \\
\hline
\end{tabular}

Notes: $p$-values in parentheses. Significance levels: ${ }^{*} p<0.05,{ }^{* * *} p<0.01,{ }^{* * * *} p<0.001$. Not reported control variables (not significant): Job occupation (private worker, self-employed, unpaid family work, government). 
is the robust positive effect of non-farm business activities of households. Even after controlling for their on average higher income compared to agrarian households, respondents in non-farm households have higher aspirations. The better access of such households to aspiration-increasing resources and networks of information can be one explanation for this observation. Interestingly, heads of household show significantly lower levels of aspirations than other household members, also when controlling for age. This can reflect a perceived 'burden of responsibility' for securing or achieving a certain level of wellbeing for the entire household, which is easier to bear when aspirations are less ambitious.

In general, we find that age and education are the most robust drivers of the respondents' aspiration gaps, while other individual or household characteristics seem less relevant for explaining aspiration. We can find only limited differences in the importance of these observable characteristics between migrants and non-migrants. However, even after controlling for a large set of economic, social, and political factors at individual, household, village and province levels, there remains a strong and significant difference in aspiration gaps between migrants and non-migrants. This implies that migrants, due to their migration experience in the past, may have generated an additional 'capacity to aspire'.

For both time horizons, it turns out that, even after controlling for a multitude of other factors, past migrants have significantly higher aspirations, with their (average) aspiration gaps being between 0.04 and 0.05 points higher than those of non-migrants ${ }^{10}$. It is though unclear whether this difference is driven by the migration experience itself, or rather by an unobserved migrant-specific disposition for higher aspirations. These two alternative explanations are now further explored.

\section{Do aspirations change as a consequence of migration?}

Table 3 provides the results of OLS regressions on changes in the respondents' aspiration gaps between the interviews in 2000 and 2007. On average, the aspiration gap has more than doubled between 2000 and 2007 (see Additional file 1), which we assume is the result of both the generally better economic prospect in 2007 compared to 2000, and the longer aspiration horizon of five years in 2007 (instead of only one year in 2000). Of key interest is the binary variable indicating whether an individual had migrated in the seven year period between the two interviews.

Overall, we find that migration between 2000 and 2007 has contributed significantly to the formation of aspirations, with an estimated migration-related increase in absolute aspiration gaps of about 0.05 points $^{11}$. Interestingly enough, the change in the aspiration gap increases significantly with the level of economic well-being in 2000. The better off are hence found more likely to generate aspirations for the future, reflecting their higher capacity to aspire and, at the same time, supporting the hypothesis of an 'aspiration trap' among the poor and less well-endowed individuals.

In a next step, we run separate estimations on sub-categories of migrants by distinguishing the reasons to migrate. We find a particularly strong rise in aspiration gaps for those migrants who moved out of economic necessity - i.e. those who mention a lack of labour market options as the main reason for migration-, whereas migrants who migrated rather for economic opportunities -i.e. those whose main reason for migration 
Table 3 Determinants of changes in aspiration gaps between 2000 and 2007

\begin{tabular}{|c|c|c|c|c|c|}
\hline \multirow{3}{*}{$D V: \Delta$ aspiration gap } & \multirow{3}{*}{$\begin{array}{c}\text { Full } \\
\text { sample } \\
\text { (1) }\end{array}$} & \multicolumn{4}{|c|}{ Type of migration } \\
\hline & & $\begin{array}{l}\text { Economic } \\
\text { opportunity }\end{array}$ & $\begin{array}{l}\text { Economic } \\
\text { necessity }\end{array}$ & Education & Marriage \\
\hline & & (2) & (3) & (4) & (5) \\
\hline \multirow[t]{2}{*}{ Migrated between 2000 - 2007} & $0.05^{* *}$ & 0.02 & $0.22^{* *}$ & $0.24^{* *}$ & 0.06 \\
\hline & $(0.018)$ & $(0.726)$ & $(0.040)$ & $(0.033)$ & $(0.236)$ \\
\hline \multirow[t]{2}{*}{ 2000: Subjective well-being } & $0.18^{* * *}$ & $0.18^{* * *}$ & $0.18^{* * *}$ & $0.18^{* * *}$ & $0.18^{* * *}$ \\
\hline & $(0.000)$ & $(0.000)$ & $(0.000)$ & $(0.000)$ & $(0.000)$ \\
\hline \multirow[t]{2}{*}{ 2007: Age group: $25-39$ years $^{\mathrm{a}}$} & 0.01 & 0.04 & 0.04 & 0.04 & 0.04 \\
\hline & $(0.570)$ & $(0.182)$ & $(0.106)$ & $(0.111)$ & $(0.166)$ \\
\hline \multirow[t]{2}{*}{ 2007: Age group: 40-65 years } & -0.03 & -0.02 & -0.01 & -0.01 & -0.01 \\
\hline & $(0.293)$ & $(0.500)$ & $(0.644)$ & $(0.633)$ & $(0.579)$ \\
\hline \multirow[t]{2}{*}{ Men } & $0.10^{* * *}$ & $0.10^{* * *}$ & $0.09^{* * *}$ & $0.09^{* * *}$ & $0.09^{* * *}$ \\
\hline & $(0.000)$ & $(0.000)$ & $(0.000)$ & $(0.000)$ & $(0.000)$ \\
\hline \multirow[t]{2}{*}{ 2000: No education ${ }^{\mathrm{b}}$} & $-0.05^{*}$ & -0.04 & -0.04 & -0.04 & -0.04 \\
\hline & $(0.065)$ & $(0.165)$ & $(0.156)$ & $(0.195)$ & $(0.174)$ \\
\hline \multirow[t]{2}{*}{ 2000: Junior high school } & -0.01 & -0.00 & -0.00 & -0.00 & 0.00 \\
\hline & $(0.815)$ & $(0.893)$ & $(0.960)$ & $(0.948)$ & $(0.917)$ \\
\hline \multirow[t]{2}{*}{ 2000: Senior high school } & 0.02 & 0.03 & 0.02 & 0.02 & 0.02 \\
\hline & $(0.387)$ & $(0.241)$ & $(0.342)$ & $(0.355)$ & $(0.368)$ \\
\hline \multirow[t]{2}{*}{ 2000: Higher education } & -0.01 & 0.01 & 0.00 & -0.00 & 0.01 \\
\hline & $(0.824)$ & $(0.899)$ & $(0.908)$ & $(0.942)$ & $(0.734)$ \\
\hline \multirow[t]{2}{*}{ Higher education completed in 2007} & 0.04 & 0.00 & 0.01 & 0.01 & 0.02 \\
\hline & $(0.183)$ & $(0.909)$ & $(0.798)$ & $(0.807)$ & $(0.572)$ \\
\hline \multirow[t]{2}{*}{ In 2007 newly employed } & 0.01 & 0.00 & 0.01 & 0.00 & 0.01 \\
\hline & $(0.668)$ & $(0.866)$ & $(0.808)$ & $(0.862)$ & $(0.545)$ \\
\hline \multirow[t]{2}{*}{ In 2007 no longer employed } & $-0.06^{* * *}$ & $-0.05^{*}$ & $-0.05^{* *}$ & $-0.05^{* *}$ & $-0.06^{* *}$ \\
\hline & $(0.009)$ & $(0.058)$ & $(0.043)$ & $(0.044)$ & $(0.029)$ \\
\hline \multirow[t]{2}{*}{ 2000: Total monthly income (In) } & -0.11 & -0.03 & -0.04 & -0.02 & -0.05 \\
\hline & $(0.553)$ & $(0.893)$ & $(0.837)$ & $(0.900)$ & $(0.798)$ \\
\hline \multirow[t]{2}{*}{ Change in total monthly income } & 0.21 & $0.29^{*}$ & $0.27^{*}$ & $0.28^{*}$ & $0.29^{*}$ \\
\hline & $(0.136)$ & $(0.058)$ & $(0.078)$ & $(0.066)$ & $(0.051)$ \\
\hline \multirow[t]{2}{*}{ 2000: Married } & $-0.09^{* * *}$ & $-0.08^{* * *}$ & $-0.08^{* * *}$ & $-0.08^{* * *}$ & $-0.08^{* * *}$ \\
\hline & $(0.000)$ & $(0.001)$ & $(0.000)$ & $(0.001)$ & $(0.000)$ \\
\hline \multirow[t]{2}{*}{ 2000: Head } & $-0.13^{* * *}$ & $-0.12^{* * *}$ & $-0.11^{* * *}$ & $-0.12^{* * *}$ & $-0.11^{* * *}$ \\
\hline & $(0.000)$ & $(0.000)$ & $(0.000)$ & $(0.000)$ & $(0.000)$ \\
\hline \multirow[t]{2}{*}{ In 2007 newly head } & $-0.07^{* * *}$ & $-0.06^{* *}$ & $-0.05^{*}$ & $-0.06^{*}$ & $-0.06^{* *}$ \\
\hline & $(0.009)$ & $(0.036)$ & $(0.078)$ & $(0.052)$ & $(0.036)$ \\
\hline \multirow[t]{2}{*}{ 2000: Household expenditure } & $0.14^{*}$ & $0.15^{*}$ & $0.14^{*}$ & $0.13^{*}$ & $0.15^{* *}$ \\
\hline & $(0.064)$ & $(0.061)$ & $(0.071)$ & $(0.089)$ & $(0.047)$ \\
\hline \multirow[t]{2}{*}{ 2000: Household expenditure squared } & $-0.02^{* *}$ & $-0.02^{* *}$ & $-0.02^{* *}$ & $-0.02^{* *}$ & $-0.02^{* *}$ \\
\hline & $(0.034)$ & $(0.027)$ & $(0.034)$ & $(0.044)$ & $(0.022)$ \\
\hline \multirow[t]{2}{*}{ Change in household expenditure } & $0.03^{* * *}$ & $0.03^{* * *}$ & $0.03^{* * *}$ & $0.03^{* * *}$ & $0.03^{* * *}$ \\
\hline & $(0.005)$ & $(0.004)$ & $(0.004)$ & $(0.004)$ & $(0.004)$ \\
\hline
\end{tabular}


Table 3 Determinants of changes in aspiration gaps between 2000 and 2007 (Continued)

\begin{tabular}{lccccc}
\hline 2000: Female-headed HH & -0.02 & -0.03 & -0.04 & -0.04 & -0.04 \\
& $(0.433)$ & $(0.260)$ & $(0.218)$ & $(0.184)$ & $(0.145)$ \\
2000: HH adults & $-0.01^{* * *}$ & $-0.01^{* * *}$ & $-0.01^{* * *}$ & $-0.01^{* * *}$ & $-0.01^{* * *}$ \\
& $(0.001)$ & $(0.001)$ & $(0.001)$ & $(0.001)$ & $(0.001)$ \\
2000: HH children & $0.02^{* * *}$ & $0.02^{* * *}$ & $0.02^{* * *}$ & $0.02^{* * *}$ & $0.02^{* * *}$ \\
& $(0.002)$ & $(0.001)$ & $(0.001)$ & $(0.001)$ & $(0.000)$ \\
2000: Rural & 0.01 & -0.00 & -0.01 & -0.01 & -0.00 \\
& $(0.488)$ & $(0.820)$ & $(0.707)$ & $(0.695)$ & $(0.936)$ \\
2000: Village: average HH asset value & $-0.04^{* * *}$ & $-0.05^{* * *}$ & $-0.05^{* * *}$ & $-0.05^{* * *}$ & $-0.05^{* * *}$ \\
& $(0.003)$ & $(0.002)$ & $(0.001)$ & $(0.001)$ & $(0.001)$ \\
2000: Relative rank asset value within the village & $-0.10^{* * *}$ & $-0.08^{* *}$ & $-0.08^{* *}$ & $-0.08^{* *}$ & $-0.08^{* * *}$ \\
& $(0.002)$ & $(0.011)$ & $(0.011)$ & $(0.012)$ & $(0.010)$ \\
Constant & 0.35 & 0.40 & $0.51^{*}$ & 0.46 & 0.46 \\
& $(0.203)$ & $(0.176)$ & $(0.089)$ & $(0.120)$ & $(0.118)$ \\
Province dummies included & Yes & Yes & Yes & Yes & Yes \\
Observations & 14006 & 12045 & 11877 & 11871 & 12166 \\
R2 / Pseudo-R2 & 0.051 & 0.049 & 0.049 & 0.049 & 0.049 \\
\hline Notes: $p$-values in parentheses. Significance levels: ${ }^{*} p<0.05,{ }^{* *} p<0.01,{ }^{* * *} p<0.001$. & & \\
The reference category in each regression are all Non-migrants, migrants for other reasons are excluded in the migration \\
type specific regressions.
\end{tabular}

was to find a better job- experienced no significant post-migration increase in aspiration gaps.

Migration for non-economic purposes, i.e. for education or marriage reasons, also has a strong positive effect on post-migration aspiration gaps. These results generate a mixed picture of the effects of migration on the adaptation of aspiration gaps. Economic migrants with more proactive attitudes to realise economic opportunities do not experience a significant post-migration increase in aspirations, whereas respondents who migrate out of economic necessity realise an increase in their 'capacity to aspire'. The same holds for migrants who moved either for educational or marriage reasons; both types of migration significantly increase aspiration gaps.

Beside these effects of migration itself, some other drivers of aspirations seem similarly relevant. A very strong effect is found for gender, indicating a highly significant 'gender gap' in changes in aspiration gaps over time with men reporting larger increases in aspiration gaps between 2000 and 2007 than women. Further, we can see that ambitions are significantly higher for younger age cohorts, which holds similarly for migrants and non-migrants.

The aspiration-enhancing effects of economic variables such as increasing income per capita or household consumption levels are positive, suggesting a 'hedonic treadmill' effect. The robust and positive effect of increasing household expenditures on changes in aspirations strengthens the assumption that there is a link between the 'capacity to realise' and the 'capacity to aspire'. Increasing economic resources hence does not only provide immediate means to realise aspirations, but may also foster aspirations for personal progress and development.

Along similar lines, we find evidence of a substantially negative effect of unemployment on the affected individuals' capacity to aspire. This might imply that within a 
rather short period of unemployment with presumably relatively stable aspirations, migration becomes more likely. However, if unemployment last longer, aspirations (as well as self-confidence, self-esteem, and even skills) may adjust downwards, and future migration (and any other proactive behaviour) becomes less of an aspired option (see e.g. Sheeran et al. 1995).

Beyond this, aspirations are also triggered through the effects of social comparisons. Our results show that an overall increase of wealth (as measured by assets) in a community has negative effects on individual aspirations. Feelings of relative deprivation, generated by an independent improvement of the average economic situation of other households, do not only negatively affect subjective well-being, but also the individual capacity to aspire. This suggests that there is only a fine line between aspirationenhancing and aspiration-deteriorating relative deprivation; for some, feelings of relative deprivation may create incentives to improve the own situation, whereas for others it may rather result in resignation. 'Minor' relative deprivation seems to be most 'effective' for triggering strong aspirations about individual progress and development.

\section{Are migrants self-selected along a predisposition of higher aspirations?}

Finally, we test whether migrants are a self-selected group of individuals who had larger aspiration gaps which exist already before migrating. We therefore decompose the initially identified difference in aspiration gaps between migrants and non-migrants into 'measurable' differences in characteristics on the one hand and a (non-measurable) disposition for higher pre-migration aspirations on the other. The panel structure of the dataset allows analysing this question. We include only those individuals with no migration experience until 2000, and compare 'permanent' non-migrants, i.e. those individuals who did also not migrate after 2000, with the group of future migrants, i.e. those non-migrants who migrated after the 2000 survey.

Table 4 reports the differences in the average aspiration gap between these two groups, who -as seen before- have on average lower aspiration gaps than those individuals with past migration experience in 2000 (Table 1). Non-migrants, who migrated after the survey in 2000, report, on average, significantly higher aspiration gaps (average gap: 0.315) than respondents with no migration experience at all (average gap: 0.389). In line with the results in Table 5, future migration is associated with higher aspirations than non-migration. However, the decisive question is whether these differences are due to individual characteristics, such as age, education or socio-economic background

Table 4 Decomposition of aspiration gaps between future migrants and non-migrants

\begin{tabular}{|c|c|c|c|c|}
\hline & \multicolumn{4}{|c|}{ Differential in aspiration gaps (Survey 2000) } \\
\hline Future non-migrants & \multicolumn{4}{|c|}{$0.315^{* * *}(0.000)$} \\
\hline Future migrants & \multicolumn{4}{|c|}{$0.389^{* * *}(0.000)$} \\
\hline \multirow[t]{2}{*}{ Differential } & \multicolumn{4}{|c|}{$-0.074^{* *}(0.002)$} \\
\hline & $\begin{array}{c}\text { Due to } \\
\text { characteristics }\end{array}$ & $\begin{array}{c}\text { Contribution } \\
\text { to differential (in \%) }\end{array}$ & Due to coefficients & $\begin{array}{c}\text { Contribution } \\
\text { to differential (in \%) }\end{array}$ \\
\hline \multirow{2}{*}{$\begin{array}{l}\text { Decomposition of } \\
\text { differential }\end{array}$} & $-0.052^{* * *}$ & \multirow[t]{2}{*}{69.77} & -0.022 & \multirow[t]{2}{*}{30.09} \\
\hline & $(0.000)$ & & $(0.359)$ & \\
\hline
\end{tabular}

$p$-values in parentheses. ${ }^{*} p<0.05,{ }^{* *} p<0.01,{ }^{* * *} p<0.001$. Decomposition includes the same set of explanatory variables as in regression on future migration (Table 3 ). 
Table 5 Determinants of future migration and the role of aspiration gaps

\begin{tabular}{|c|c|c|c|c|c|}
\hline \multirow{2}{*}{ DV: Migrated in 2000-02 } & \multirow[b]{2}{*}{ Full sample } & \multicolumn{4}{|c|}{ Type of migration } \\
\hline & & $\begin{array}{c}\text { Economic } \\
\text { opportunity }\end{array}$ & $\begin{array}{l}\text { Economic } \\
\text { necessity }\end{array}$ & Education & Marriage \\
\hline \multirow{2}{*}{ Positive aspiration gap } & $0.11^{* *}$ & $0.30^{* *}$ & -0.23 & 0.20 & -0.10 \\
\hline & $(0.046)$ & $(0.016)$ & $(0.334)$ & $(0.170)$ & $(0.616)$ \\
\hline \multirow{2}{*}{ Past migration experience } & $0.82^{* * *}$ & $0.78^{* * *}$ & 0.36 & $0.40^{* *}$ & 0.13 \\
\hline & $(0.000)$ & $(0.000)$ & $(0.146)$ & $(0.013)$ & $(0.583)$ \\
\hline \multirow{2}{*}{ Age group: 25-39 years ${ }^{a}$} & $-0.46^{* * *}$ & $-0.84^{* * *}$ & $-1.31^{* * *}$ & $-0.52^{* * *}$ & $-2.07^{* * *}$ \\
\hline & $(0.000)$ & $(0.000)$ & $(0.000)$ & $(0.006)$ & $(0.000)$ \\
\hline \multirow{2}{*}{ Age group: $40-65$ years } & $-1.08^{* * *}$ & $-1.15^{* * *}$ & $-2.28^{* * *}$ & $-2.46^{* * *}$ & $-3.13^{* * *}$ \\
\hline & $(0.000)$ & $(0.000)$ & $(0.000)$ & $(0.000)$ & $(0.000)$ \\
\hline \multirow{2}{*}{ Men } & 0.03 & $0.55^{* * *}$ & $0.87^{* * *}$ & $-0.66^{* * *}$ & -0.01 \\
\hline & $(0.572)$ & $(0.000)$ & $(0.000)$ & $(0.000)$ & $(0.951)$ \\
\hline \multirow{2}{*}{ No education ${ }^{b}$} & $-0.57^{* * *}$ & -0.65 & 0.58 & 0.19 & \\
\hline & $(0.003)$ & $(0.177)$ & $(0.322)$ & $(0.680)$ & \\
\hline \multirow{2}{*}{ Junior high school } & $0.32^{* * *}$ & 0.22 & -0.09 & -0.12 & $0.93^{* *}$ \\
\hline & $(0.000)$ & $(0.253)$ & $(0.763)$ & $(0.586)$ & $(0.050)$ \\
\hline \multirow{2}{*}{ Senior high school } & $0.68^{* * *}$ & $0.86^{* * *}$ & 0.25 & 0.32 & $2.34^{* * *}$ \\
\hline & $(0.000)$ & $(0.000)$ & $(0.433)$ & $(0.138)$ & $(0.000)$ \\
\hline \multirow{2}{*}{ Higher education } & $0.61^{* * *}$ & $0.79^{* * *}$ & -0.70 & $0.72^{* *}$ & $1.26^{* *}$ \\
\hline & $(0.000)$ & $(0.006)$ & $(0.265)$ & $(0.014)$ & $(0.038)$ \\
\hline \multirow{2}{*}{$\begin{array}{l}\text { Education gap: own vs. highest } \\
\text { education in } \mathrm{HH}\end{array}$} & 0.05 & 0.13 & -0.06 & -0.02 & $0.77^{* * *}$ \\
\hline & $(0.261)$ & $(0.251)$ & $(0.756)$ & $(0.865)$ & $(0.000)$ \\
\hline \multirow{2}{*}{ Income (In) } & 0.01 & 0.03 & 0.04 & 0.02 & -0.04 \\
\hline & $(0.329)$ & $(0.183)$ & $(0.285)$ & $(0.517)$ & $(0.401)$ \\
\hline \multirow{2}{*}{ Participation in community meetings } & -0.12 & -0.13 & -0.08 & 0.15 & -0.13 \\
\hline & $(0.137)$ & $(0.490)$ & $(0.811)$ & $(0.491)$ & $(0.711)$ \\
\hline \multirow{2}{*}{ Married } & $-0.42^{* * *}$ & $-1.28^{* * *}$ & $-1.16^{* * *}$ & $-2.85^{* * *}$ & $-1.75^{* * *}$ \\
\hline & $(0.000)$ & $(0.000)$ & $(0.000)$ & $(0.000)$ & $(0.000)$ \\
\hline \multirow{2}{*}{$\mathrm{HH}$ head } & 0.04 & 0.32 & $0.90^{* *}$ & $0.49^{* *}$ & $1.48^{* * *}$ \\
\hline & $(0.625)$ & $(0.109)$ & $(0.014)$ & $(0.048)$ & $(0.000)$ \\
\hline \multirow{2}{*}{ Household expenditure } & -0.20 & 0.26 & 0.23 & -0.13 & 1.14 \\
\hline & $(0.409)$ & $(0.670)$ & $(0.821)$ & $(0.837)$ & $(0.293)$ \\
\hline \multirow{2}{*}{ Household expenditure squared } & 0.01 & -0.07 & -0.07 & -0.01 & -0.09 \\
\hline & $(0.639)$ & $(0.348)$ & $(0.590)$ & $(0.885)$ & $(0.446)$ \\
\hline \multirow{2}{*}{ Household with farm production } & $-0.24 * * *$ & 0.04 & -0.09 & -0.01 & 0.31 \\
\hline & $(0.000)$ & $(0.820)$ & $(0.724)$ & $(0.941)$ & $(0.192)$ \\
\hline \multirow{2}{*}{ Household with non-farm business } & -0.05 & -0.02 & 0.14 & -0.09 & 0.27 \\
\hline & $(0.386)$ & $(0.905)$ & $(0.535)$ & $(0.570)$ & $(0.183)$ \\
\hline \multirow{2}{*}{ Female household head } & -0.08 & 0.15 & 0.37 & $-0.41^{* *}$ & -0.24 \\
\hline & $(0.288)$ & $(0.367)$ & $(0.184)$ & $(0.038)$ & $(0.425)$ \\
\hline \multirow{2}{*}{$\mathrm{HH}$ adults } & $-0.03^{* *}$ & -0.05 & 0.02 & 0.03 & -0.08 \\
\hline & $(0.013)$ & $(0.160)$ & (0.635) & $(0.256)$ & $(0.154)$ \\
\hline \multirow{2}{*}{$\mathrm{HH}$ children } & -0.01 & 0.06 & -0.09 & -0.04 & 0.02 \\
\hline & $(0.660)$ & $(0.230)$ & $(0.311)$ & $(0.455)$ & $(0.848)$ \\
\hline
\end{tabular}


Table 5 Determinants of future migration and the role of aspiration gaps (Continued)

\begin{tabular}{lccccc}
\hline Economic shock in the last three years & 0.01 & 0.18 & -0.04 & 0.18 & 0.17 \\
& $(0.893)$ & $(0.266)$ & $(0.895)$ & $(0.354)$ & $(0.555)$ \\
Other shock in the last three years & 0.08 & -0.22 & -0.24 & 0.26 & 0.31 \\
& $(0.262)$ & $(0.266)$ & $(0.490)$ & $(0.173)$ & $(0.229)$ \\
Rural & -0.06 & $0.42^{* * *}$ & $0.59^{* *}$ & -0.00 & 0.23 \\
& $(0.380)$ & $(0.007)$ & $(0.030)$ & $(0.994)$ & $(0.329)$ \\
Average HH asset value & $-0.08^{* * *}$ & $-0.15^{* * *}$ & 0.05 & -0.09 & -0.07 \\
& $(0.002)$ & $(0.008)$ & $(0.697)$ & $(0.219)$ & $(0.469)$ \\
Constant & -0.03 & -1.30 & $-5.45^{*}$ & -1.80 & $-7.14^{* *}$ \\
Province dummies included & $(0.971)$ & $(0.408)$ & $(0.060)$ & $(0.315)$ & $(0.014)$ \\
Observations & Yes & Yes & Yes & Yes & Yes \\
Pseudo-R2 & 21512 & 20428 & 19017 & 20368 & 8755 \\
\hline
\end{tabular}

Notes: Reference Category: All Non-Migrants in 2000. Job categories included (private worker, self-employed, unpaid Family work, government).

(or any other variables we control for), or whether these differences are due to an (non-measurable) natural disposition for relatively high aspirations.

To investigate the relative importance of these two explanations, we decompose the overall difference in the aspiration gap (0.074). We apply a Blinder-Oaxaca decomposition (Blinder, 1973; Oaxaca, 1973), which divides the differential in aspiration gaps into the part that is explained by the set of observable characteristics, i.e. the set of explanatory variables, and a residual part that cannot be accounted for by differences in these characteristics (Jann, 2008). Hereby, the unobserved predictors reflect a natural disposition of (future) migrants for higher aspirations that go beyond observed characteristics. This decomposition technique hence allows answering the following question about the counterfactual: "what would the average aspiration gap for future migrants have been if they would have had the same observable characteristics as non-migrants?" The decomposition follows the following formulation:

$$
\widehat{\Delta G}_{N, F}=\bar{X}_{N}^{\prime}\left(\hat{\beta}_{F}-\hat{\beta}_{N}\right)+\hat{\beta}_{F}\left(\bar{X}_{F}^{\prime}+\bar{X}_{N}^{\prime}\right)
$$

where $\widehat{\Delta G}_{N, F}$ reflects the differential in average aspiration gaps of future migrants and non-migrants, $\bar{X}_{F}^{\prime}$ and $\bar{X}_{N}^{\prime}$ are vectors of mean observable characteristics for the two respective groups, and $\hat{\beta}_{F}$ and $\hat{\beta}_{N}$ are the estimated vectors of coefficients, respectively.

Our estimation results show that about 70 per cent (0.052) of the overall differential in aspirations (0.074) can be explained by the differences in observable characteristics (Table 6). We can identify three main categories in which future migrants have favourable, aspiration-inducing characteristics: age, education, and the geographical location (here: province) explain most of the larger aspiration gaps among future migrants.

If future migrants would have had exactly the same observable characteristics as nonmigrants, the between-group aspiration differential would have been 0.022 , or about 30 per cent of the actual difference. As this residual is due to differences in unobservable, 
Table 6 Future migration and alternative aspiration gaps

\begin{tabular}{lccccc}
\hline & $\begin{array}{c}(\mathbf{1}) \\
\text { Full sample }\end{array}$ & $\begin{array}{c}\mathbf{( 3 )} \\
\text { Economic } \\
\text { opportunity }\end{array}$ & $\begin{array}{c}\mathbf{( 4 )} \\
\text { Economic } \\
\text { necessity }\end{array}$ & $\begin{array}{c}\text { (5) } \\
\text { Education }\end{array}$ & $\begin{array}{c}\text { (6) } \\
\text { Marriage }\end{array}$ \\
\hline Panel 1: Migration within 2 years (2000-2002) & & & & & \\
Dummy: moderate aspirations (Gap =1) & $0.10^{*}$ & $0.31^{* *}$ & -0.14 & 0.22 & -0.05 \\
& $(0.087)$ & $(0.018)$ & $(0.559)$ & $(0.130)$ & $(0.828)$ \\
Dummy: high aspirations (Gap > 1) & 0.20 & 0.26 & -1.38 & -0.02 & -0.79 \\
& $(0.115)$ & $(0.385)$ & $(0.173)$ & $(0.954)$ & $(0.281)$ \\
Panel 2: Migration within 1 year (2000-2001) & 0.13 & $0.37^{*}$ & -0.42 & 0.18 & -0.25 \\
Dummy: moderate aspirations (Gap =1) & $(0.147)$ & $(0.061)$ & $(0.242)$ & $(0.482)$ & $(0.503)$ \\
& -0.07 & -0.32 & -0.77 & -1.18 & 0.29 \\
Dummy: high aspirations (Gap > 1) & $(0.758)$ & $(0.594)$ & $(0.454)$ & $(0.248)$ & $(0.701)$ \\
\hline
\end{tabular}

Note: Model and other control variables as in Table 4. Reference Category: All Non-Migrants in 2000.

individual-specific dispositions for higher aspirations, we can conclude that (future) migrants are neither a representative group for the total population nor are they representative for the (sub-)population with favourable 'migration characteristics' such as young age, unmarried, well-educated, and with decent socio-economic background. Instead, migrants have some (unobserved) qualities that generate higher aspirations already before migrating, compared to those individuals who never migrate. Potential migrants are hence self-selected along a strong 'capacity to realise' and a unique 'capacity to aspire'.

\section{Do aspirations trigger migration?}

We are now turning to an alternative explanation for why migrants have significantly higher aspirations than non-migrants. We hypothesised that migrants show significantly higher aspirations already before migration. Individuals with a higher capacity to aspire are hence more likely to consider migration as a valuable option to realise their aspirations for increased economic well-being. Table 5 therefore reports the results of the effects of pre-migration aspirations on the decision to migrate. We use the longitudinal dimension of the dataset to identify those respondents who migrate in the years after the interview in 2000 (IFLS3).

We use the full sample of respondents for which data from IFLS3 and IFLS4 is available and define all individuals who did not migrate in the first two years after IFLS 3 as the reference group. Importantly, we do control for past migration (before IFLS3) to account for the positive effect of migration experiences on aspirations identified above. Specification (1) in Table 5 estimates the odds-ratios that an individual will migrate within two years, given his or her aspiration gap at the time of the 2000 survey. Overall, we find that individuals with a positive aspiration gap have a significantly higher propensity to migrate compared to individuals without positive aspirations for the near future. By considering different types of migration, we observe that migration for reasons of economic opportunity is particularly driven by aspirations for economic well-being. Individuals with positive aspirations for their future economic well-being are more 
likely to move in order to reap benefits from job opportunities elsewhere. For migrants who are rather compelled to resettle due to economic necessity, however, future aspirations to not have a significant effect on the decision to migrate.

Furthermore, we find strong evidence for migration being primarily an option of young, unmarried and well-educated people. This group has a comparative advantage in the capacities to aspire and to realise, which makes them predestined as potential migrants. Age in particular is an important factor in migration decision-making, and this not only for economic reasons of expanding the time available for amortising migration costs and optimising life-time income, but maybe more for social reasons of being unmarried and not responsible for accommodating a family.

Furthermore, a substantial positive effect of past migration on the likelihood of future migration decisions seems to confirm a certain self-selection into a (temporary) 'migration lifestyle', which may reflect some path-dependency in individual migration histories, at least until age and family responsibilities counteract this personal inclination for migration. Finally, moving out of rural areas is not a general trend in Indonesia, but becomes only relevant when economic opportunities are lacking and people do not find alternative ways for improving economic-well-being. This interpretation is supported by the negative effect of average wealth in a community on out-migration propensity of its members. Wealthier communities which provide more economic opportunities experience less out-migration.

\section{Is the aspiration-migration relationship non-linear?}

Finally, we address the question of whether individuals with moderate aspirations have a higher migration propensity than individuals with very low or very high aspirations. In order to test the existence of such a non-linear relationship between aspirations and future migration decisions, we re-run the models presented in Table 5 and replace the single dummy for positive aspirations with two dummies for moderate and high aspirations, respectively. Table 6 presents the coefficients for these dummies (all other control variables as in Table 5 though not reported).

When looking at migration movements in the first two years after the 2000 survey (Panel 1), this non-linear relationship can be observed for migration motivations related to seeking economic opportunities as well as, though only marginally significant, migration for educational purposes. The pattern, however, is not particularly clear and results for the full sample even suggest a positive and linear relationship. We therefore rerun the analysis for migration movements within the first year after the survey to match the time period of the stated aspiration gap (Panel 2). While the number of observed migration movements drops from 1,635 to 840, the effect of future aspirations (which were stated for the next coming year) may be assessed more accurately this way. The drop in observed migration movements causes the expected loss of significance; however, we do find a distinct non-linear relationship between aspirations and migration, with very high aspirations for the future reducing the likelihood of migration (though not significantly). This result seems to corroborate the hypothesis that 'middle- 
range' aspirations trigger migration propensities most. Low or extremely ambitious aspirations, however, seem to make migration less of an option.

\section{Conclusion}

The main conclusion of this study is that aspirations are a pre-requisite, but can also be a consequence of migration. Aspirations can be a decisive 'mental capability' to avoid or to escape socio-economic traps such as poverty, unemployment, or social and economic exclusion. However, where do aspirations come from? Our study suggests at least four main sources for aspirations: first, fortune of being born with a natural capacity to aspire, second, fortune of being born into a well-situated household providing the economic, social and human resources necessary to develop an aspirational personality, third, being young and having enjoyed some education and become more independent from the social context born into, and fourth, proactive behaviour such as migration itself, which can further increase aspirations for the future.

Consequently, the allocation of aspirations is not random across the populations, and therefore, migration is a self-selected process with regards to aspiration levels. Migrants have higher aspirations and we find strong evidence that while these aspirations are partly the result of the migration experience itself, they also had already existed before migration. Higher levels of aspirations, by which migrants are self-selected, are mainly driven (i.e. by about 70 per cent) by aspiration-enhancing characteristics such as being of young age, well-educated, and economically and socially well-situated. However, the residual is more or less due to unobservable characteristics which we assume to be captured by an individual's personality and a natural inclination for migration.

This research has some important policy implications. In general, socio-economic development, including poverty reduction, facilitates the individual capacity to realise further behavioural actions, such as investment in physical, social or human capital. Moreover, development also spurs the individual capacity to aspire individual and societal progress and development. In that sense, development is self-perpetuating as soon as it is initiated. As far as migration is concerned, we can expect that aspirationenhancing development also spurs migration intentions, thereby leading to a more mobile society with supposedly more internal and international migration. Migration experience feeds back into individual future aspirations. However, there are limits to migration as a self-enhancing social process. Ageing societies, of which also countries like Indonesia begin to 'suffer', have smaller cohorts of younger people; this reduces the number of potential migrants in the future. And, significant numbers of individuals do not have a natural disposition for aspirations, i.e. in all societies, a significant number of individuals never consider or aspire migration as an option for improving their lot.

\section{Endnotes}

${ }^{1}$ Although in general aspiration gaps are expected to be positive, it is at least possible that sometimes people's aspirations are lower than their current status quo. For instance, this seems possible in situations where people have done unexpectedly well in the recent past and they either haven't adjusted their aspirations upwards, or they realise that the current level of well-being is rather temporary and significantly above their long-term base level. 
${ }^{2}$ One referee pointed to another explanation for higher aspirations of migrants, which is known in the cognitive science literature as the 'confirmation bias' by which people actively seek for reasons or information that will confirm or justify their past decision (e.g. to migrate). Information that will disconfirm is ignored in order to avoid cognitive dissonance.

${ }^{3}$ Wilson's (1987) study on role models shows that the effect can also work in the other direction. He shows that successful individuals who were leaving the inner city did not influence the aspirations of those who stayed; thus, out-migrants were not part of the aspirational window of the stayers anymore (Ray 2006).

${ }^{4}$ An IFLS community/village refers to an enumeration area (EA) that was randomly chosen from a nationally representative sample frame used in the 1993 SUSENAS survey. Each EA includes between 200 and 300 households (Strauss et al. 2004). The fact that we avail of a representative sample for a large population is important as it is rare in this literature, where most micro-studies are either concentrated geographically or correspond to non-random, small laboratory sets of subjects.

${ }^{5}$ Additional file 1 gives an overview of migration movements of IFLS respondents between IFLS2 and IFLS3, and IFLS3 and IFLS4, respectively.

${ }^{6}$ The IFLS module on subjective well-being asks the following two questions: "Please imagine a six-step ladder where on the bottom (the first step), stand the poorest people, and on the highest step (the sixth step), stand the richest people. On which step are you today?" and "On which step do you expect to find one (five) years from now?"

${ }^{7}$ Additional file 1 reports the average level of the aspiration gap by current levels of well-being.

${ }^{8}$ This result on levels of subjective well-being differs slightly from other contexts like China (Knight \& Gunatilaka 2010) or Nepal (Fafchamps \& Shilpi 2008).

${ }^{9}$ We run standard OLS regression models to estimate the determinants of the aspiration gap. While the aspiration gap variable is a discrete variable for which ordered logit or probit estimations would be the standard regression approach, we run OLS regressions as the interpretation of the estimated coefficients is more straightforward. Results of both approaches are very similar, which is in line with Ferrer-i-Carbonell and Frijters (2004), who have demonstrated that the use of OLS leads to negligibly different results for an 11-point scale (aspiration gap between -5 and 5 ).

${ }^{10}$ In comparison with the results in Table 1, these numbers show that the actual aspiration gap between migrants and non-migrants halves when controlling for other possible aspiration-enhancing factors.

${ }^{11}$ The simultaneity between the decision to migrate (between 2000 and 2007) and the change in the aspiration gap over the same time period may bias the estimates when aspirations have already changed before the migration experience. We therefore provide two approaches to assess the robustness of our findings. First, we instrument for migration using recent migration experience of the respondent's parents as an instrument for (current) migration of the individual, as the past migration experience of close household members is likely to have a positive impact on future migration, but should have no influence on the future change in the aspiration gap. The IV estimates (available from the authors upon request) confirm a significantly positive impact of migration on the change in the aspiration gap is confirmed. Second, we address the issue of simultaneity by considering only those migration movements that occurred in the first four years after the 2000 survey. While we still cannot preclude that aspirations 
have changed already before the migration experience, the sequencing is clearer in this set-up. The estimated effects are similar to (and in part even stronger than) the OLS estimates. We are therefore confident that the effect runs from the migration experience to increased aspirations, rather than vice versa.

\section{Additional file}

Additional file 1: Appendix. Table A1. Descriptive Statistics. Table A2. Average aspiration Gaps by current level of subjective well-being.

\section{Competing interests}

The IZA Journal of Migration is committed to the IZA Guiding Principles of Research Integrity. The authors declare that they have observed these principles.

Responsible editor: Amelie F Constant

Received: 13 October 2013 Accepted: 13 January 2014

Published: 29 Jan 2014

\section{References}

Appadurai, A. 2004. The Capacity to Aspire: Culture and the Terms of Recognition. In Culture and Public Action, ed. V Rao and M Walton. Stanford, CA: Stanford University Press.

Blinder, AS. 1973. Wage discrimination: reduced form and structural estimates. Journal of Human resources: 436-455.

Carling, J. 2002. Migration in the age of involuntary immobility: theoretical reflections and Cape Verdean experiences. Journal of Ethnic and Migration Studies 28(1): 5-42.

Carling, J. 2004. Emigration, return and development in Cape Verde: the impact of closing borders. Population, Space and Place 10(2): 113-132. doi:10.1002/psp.322.

Collier, G. 1994. Social origins of mental ability. New York: Wiley.

Dalton, PS, S Ghosal, and A Mani. 2010. Poverty and aspirations failure, CAGE Online Working Paper Series.

de Haas, H. 2010. Migration and development: a theoretical perspective1. International Migration Review 44(1): 227-264. doi: 10.1111/j.1747-7379.2009.00804.x.

Fafchamps, M, and F Shilpi. 2008. Subjective welfare, isolation, and relative consumption. Journal of Development Economics 86(1): 43-60.

Ferrer-i-Carbonell, A, and P Frijters. 2004. 'How important is methodology for the estimates of the determinants of happiness? The Economic Journal 114: 641-659.

Greenwood, MJ. 1997. Internal migration in developed countries. Handbook of population and family economics 1: $647-720$.

Jann, B. 2008. The Blinder-Oaxaca decomposition for linear regression models. Stata Journal 8(4): 453-479.

Knight, J, and R Gunatilaka. 2010. Great expectations? The subjective well-being of rural-urban migrants in China. World Development 38(1): 113-124. doi: 10.1016/j.worlddev.2009.03.002.

Lucas, REB. 1997. Internal migration in developing countries. Handbook of population and family economics 1: 721-798.

Marr, C. 1990. Uprooting people, destroying cultures. Indonesia's transmigration program. Multinational Monitor 11(10). Nations, U. 2008. An Overview of Urbanisation, Internal Migration, Population Distribution and Development in the World. United Nations Expert group Meeting on Population Distribution, Urbanisation, Internal Migration and Development, UN/POP/EGM-URB/2008/01.

Oaxaca, R. 1973. Male-female wage differentials in urban labor markets. International Economic Review 14(3): 693-709.

Østby, G, H Urdal, MZ Tadjoeddin, SM Murshed, and H Strand. 2011. Population pressure, horizontal inequality and political violence: a disaggregated study of Indonesian Provinces, 1990-2003. Journal of Development Studies 47(3): 377-398.

Quaglia, RJ, and CD Cobb. 1996. Toward a theory of student aspirations. Journal of Research in Rural Education 12(3): 127-132.

Rao, V, and M Walton. 2004. Introduction: culture and public action, 3-36. Culture and Public Action: A CrossDisciplinary Dialogue on Development Policy.

Ray, D. 2006. Aspirations, poverty, and economic change. In Understanding poverty, ed. AV Banerjee, R Bénabo, and D Mookherjee, 409-421. Oxford University Press.

Selten, R. 1998. Aspiration adaptation theory. Journal of Mathematical Psychology 42(2-3): 191-214. doi: 10.1006/ jmps.1997.1205.

Sen, A. 1985. Well-being, agency and freedom: the dewey lectures 1984. The Journal of Philosophy 82(4): 169-221.

Sheeran, P, D Abrams, and S Orbell. 1995. Unemployment, self-esteem, and depression: a social comparison theory approach. Basic and Applied Social Psychology 17(1-2): 65-82.

Stark, O, and JE Taylor. 1991. Migration incentives, migration types: the role of relative deprivation. Economic Journal 101(408): 1163-1178.

Strauss, J, K Beegle, B Sikoki, A Dwiyanto, Y Herawati, and F Witoelar. 2004. The third wave of the Indonesia Family Life Survey (IFLS3): Overview and field report. NIA/NICHD. 
Strauss, J, F Witoelar, B Sikoki, and AM Wattie. 2009. The Fourth Wave of the Indonesia Family Life Survey: Overview and Field Report Volume 1, RAND Labor and Population Working Paper WR-675/1-NIA/NICHD. Santa Monica, CA: RAND.

Van Lottum, J, and D Marks. 2010. The determinants of internal migration in a developing country: quantitative evidence for Indonesia, 1930-2000. Applied Economics 44(34): 4485-4494

Volkstelling. 1930. Landsdrukkerij. Batavia.

Wilson, WJ. 1987. The Truly Disadvantaged: The Inner City, The Underclass, and Public Policy. Chicago: London. Worldbank. 2011. Current Challenges, Future Potential. Indonesia Economic Quarterly.

10.1186/2193-9039-3-1

Cite this article as: Czaika and Vothknecht: Migration and aspirations - are migrants trapped on a hedonic treadmill? IZA Journal of Migration 2014, 3:1

Submit your manuscript to a SpringerOpen ${ }^{\circ}$ journal and benefit from:

- Convenient online submission

- Rigorous peer review

- Immediate publication on acceptance

- Open access: articles freely available online

- High visibility within the field

- Retaining the copyright to your article 